\title{
В.Е. Миронова
}

\section{РЕЦЕПЦИЯ ДЕТЕКТИВНОГО ТВОРЧЕСТВА АРТУРА КОНАН ДОЙЛА В РУССКОЙ ЛИТЕРАТУРЕ: К ПОСТАНОВКЕ ВОПРОСА}

\begin{abstract}
В статье формулируется проблема рецепции детективньх произведений английского писателя Артура Конан Дойла в России. В контексте отношения русских писателей и критиков к детективным произведениям в целом выявляются основные уровни восприятия творчества Конан Дойла, выделяются этапы реиепции детективных новелл писателя в России.

Ключевые слова: Артур Конан Дойл, рецепция, уровни восприятия, детективная новелла, русская литература.
\end{abstract}

Творчество английского писателя Артура Конан Дойла (1859-1930) представляет особый интерес в контексте истории развития русско-английских литературных взаимосвязей начиная с конца XIX в. до наших дней. Несмотря на тот факт, что Конан Дойл является автором произведений различных жанров, его имя чаще всего ассоциируется с детективом.

Рассматривая роль и место Артура Конан Дойла в процессе развития детективного жанра, следует отметить, что он в значительной мере способствовал формированию канонов английского детектива, опубликовав роман «Этюд в багровых тонах» в 1887 г. и первые два сборника новелл: «Приключения Шерлока Холмса» и «Записки о Шерлоке Холмсе» в 1892 г. Созданный в них образ сыщика, обладающего живым умом, интеллектом и логическим мышлением, оставался архетипической фигурой на протяжении XX столетия [1. C. 142]. Холмс раскрывает преступления не только для торжества справедливости, но и ради неиссякаемого любопытства, интереса к новым сложным делам. Он охотно делится своими знаниями с теми, кому небезразличны трудные задачи, загадки, демонстрируя оригинальный ход мысли. Таким образом, Холмс стал художественным воплощением британца, интеллектуала, невозмутимого в самых неожиданных ситуациях.

Этому герою посвящены четыре произведения, жанр которых сам писатель характеризует как романы: «Этюд в багровых тонах», «Знак четырех», «Собака Баскервилей», «Долина ужаса» и пять 
сборников новелл. Кроме двух названных выше, это «Возвращение Шерлока Холмса», «Его прощальный поклон» и «Архив Шерлока Холмса». Примечательно, что почти все новеллы о Шерлоке Холмсе построены по одной схеме: вступление, в котором предстает образ мудрого и неординарного сыщика; появление пострадавшего лица, чей рассказ наводит на ложный след, и удивительное, непредсказуемое раскрытие преступления. Важно упомянуть, что в произведениях о Шерлоке Холмсе не всегда имеет место настоящее преступление: главный герой, как правило, нарушает закон, но часто моральный, нравственный, а не правовой. Зачастую в произведениях о Шерлоке Холмсе не происходит очевидного нарушения правового закона (убийство, мошенничество или другое), а имеет место обман, предательство, равнодушие, за которое человек, его совершивший, не несет уголовной ответственности, однако причиняет боль и страдание другим, что вызывает негативное отношение к нему общества. При этом настоящих преступников Шерлок Холмс порой в определенной степени оправдывает, он сочувствует и симпатизирует им как людям, пережившим несчастье или столкнувшимся с несправедливостью, вынужденным совершить проступок.

Большой интерес к произведениям о Шерлоке Холмсе вызван также нарративным талантом Конан Дойла. При знакомстве с его творчеством читатель, безусловно, получает эстетическое удовольствие и, кроме того, знакомится с образом жизни, традициями англичан конца XIX в.

Фигура Конан Дойла вызывала не меньший интерес, чем созданный им образ детектива. Автор новелл о Шерлоке Холмсе был человеком образованным, достаточно хорошо осведомленным в точных науках, таких как химия и физиология. Писатель был близко знаком с профессором Беллем, прославившимся тем, что мог получить информацию о жизни своих пациентов на основе незначительных деталей, например цвета лица, элементов гардероба и т.д. В Шерлоке Холмсе подобное качество является одним из основных, характеризующих его личность. Говоря о творчестве Конан Дойла, особенно следует подчеркнуть, что его творческая и литературная позиция были сформированы в Викторианскую эпоху. Писатель являлся ярким представителем английской общественной и политической традиции, принимал активное участие в деятельности различных литературных клубов, имел собственное представление о реформах, ко- 
торые, с его точки зрения, необходимо проводить в Англии, в частности реформы в армии, судебной практике и правовой системе.

При такой популярности неудивительно, что личность Конан Дойла привлекала как читателей, так и критиков и писателей во всем мире; его биография содержит ряд интересных фактов, которые, несомненно, отразились на стиле и содержании его произведений. Незаурядный ум, харизматический характер Конан Дойла вызывали множество споров и дискуссий. Отношение к писателю лично и к его работам во всем мире неоднозначно. С одной стороны, отмечается невероятная популярность его детективных произведений, с другой - резкая критика, осуждение и причисление его детективного творчества к классу низкосортной литературы.

Предлагаемая статья посвящена рассмотрению вопроса о восприятии детективного творчества Артура Конан Дойла в России. Изучение рецепции детективных произведений английского писателя представляется значимым для нас с точки зрения становления и развития эстетики, поэтики и типологии жанра детектива в английской и русской литературе. Кроме того, необходимо осмыслить принципы, характер и эволюцию восприятия детективных новелл Конан Дойла русскими писателями и переводчиками, выделяя основные уровни и этапы рецепции творчества английского автора. Каждый из этапов данной рецептивной истории имеет свою специфику и логику развития, что соответствует современному интересу к проблемам компаративистики, теории и истории перевода, рецептивной эстетики, русско-английского литературного взаимодействия.

Поскольку в данной работе особое внимание уделяется детективному жанру, необходимо, прежде всего, предоставить его определение и общую характеристику. Детективом (от англ. detective сыщик; лат. detectio - раскрытие) называют художественное произведение с особым типом построения сюжета, в основе которого лежит реализованный в раскрытии преступления конфликт добра и зла, разрешающийся победой добра [2]. Традиционно оно определяется как ответвление приключенческой литературы, посвященное раскрытию загадочных преступлений.

Детектив как литературный жанр сформировался в Великобритании во второй половине XIX в., хотя его появление традиционно связывают с именем американского писателя Э. По, который в но- 
веллах 1840-х гг. описал технику дедуктивного метода, разработал множество детективных сюжетных ходов, впервые вывел образ детектива-любителя, наделенного необыкновенными способностями к логическому анализу (например, в новелле «Убийство на улице Морг» (1841). Французская литературная традиция детектива связана с именами Э. Габорио, Г. Леру, М. Леблан, в то время как в Англии наиболее значимыми представителями данного жанра являлись Г. Честертон, Э. Уоллес, но прежде всего А. Конан Дойл.

Социально-эстетический феномен детективной литературы привлекал внимание многих исследователей, писателей и издателей, таких как А.З. Вулис, А.Г. Адамов, Я.К. Маркулан, Г.А. Анджапаридзе, Б.Н. Райнов, Г. Хестхейи, С.М. Эйзенштейн и др. (не считая исследователей, изучающих элементы детектива, являющиеся неотъемлемой частью многих произведений «большой» литературы, например романов Ф.М. Достоевского, О. Бальзака, Ч. Диккенса и т.д.). Однако единой общепризнанной теории детективного жанра на данный момент не существует. Одни называют его интеллектуальным кроссвордом, другие - смешением литературы и игры, третьи производственным романом из жизни работников уголовного розыска.

В русской литературе детектив появился лишь в 70-х гг. XIX в. Несмотря на то, что тема преступления всегда интересовала русских писателей и читателей, она часто развивалась в произведениях других жанров, но только совокупность определенных факторов способствовала возникновению в русской литературной традиции детектива как самостоятельного жанра. В частности, в России второй половины XIX в. происходили такие неоднозначные события, как стремительная урбанизация, интенсивное капиталистическое развитие, судебная реформа. В газетах и журналах печатались очерки и репортажи из зала суда, которые активно обсуждались читателями. Однако в это время детектив еще не занял достойного места в жанровой системе русской литературы, был не способен конкурировать с более «серьезными», каноническими жанрами. Детективные рассказы печатались в основном в дешевых изданиях, низовых газетах. Считалось, что детективные рассказы писали те, у кого недостаточно либо таланта, либо образования. Понятно, что их произведения подвергались резкой критике. Только с появлением переводов французских и английских детективных произведений на русский язык (в 
1860-е гг.) отношение к детективному жанру в России значительно изменилось. Появляются произведения о расследованиях уголовного дела: «Концы в воду» Н.Д. Ахшарумова, «Убийство в деревне Медведице» А.С. Панова, «Рассказы следователя» А.А. Шкляревского и др. [3. С. 6], начинают выходить бесплатные приложения к газетам и журналам, где печатаются в основном переводные детективы. Средние социальные слои, такие как купцы, студенчество, чиновники, находили эти книги весьма интересными и познавательными. Не случайно исследователи определяют 1860-1870-е гг. как «период становления жанра криминального романа на русской почве, который развивался преимущественно в массовой литературе» [4. С. 67].

Значительные перемены в становлении русского детективного жанра произошли в начале XX в., когда распространение приобрели произведения, в которых главным героем являлся сыщик, успешно раскрывающий преступления. В этот период детектив стал абсолютно полноценным жанром, популярность которого в России, безусловно, непосредственно связана с рецепцией творчества Конан Дойла.

Однако первые переводы отдельных произведений английского писателя были сделаны в России еще в конце XIX в. Так, например, новелла «Пестрая лента» появилась в 1893 г. под названием «Пестрая банда» в еженедельном иллюстрированном художественнолитературном журнале «Звезда», выходившем с 1886 г. Это же произведение было опубликовано несколькими годами позже, в 1896 г., в «Литературном приложении "Нивы”». Имена переводчиков неизвестны. В 1894 г. в январском номере «Звезды» появляется другая, не менее популярная новелла «Изумрудная диадема», а в 1897 г. переводы этого же произведения были опубликованы в журналах «Нива» под названием «Корона с бериллами» и «Север» под названием «Опаловая диадема». Имена выполнивших первые два перевода неизвестны, а перевод для журнала «Север» подписан криптонимом Б.Е. В 1894 г. также в журнале «Звезда» был напечатан перевод новеллы «Голубой карбункул», в 1899 г. публикуется еще один ее перевод под названием «Алмаз графини Моркар» в еженедельном воскресном приложении к газете «Сын отечества» (переводчик В. Бернаскони), а в 1901 г. в журнале «Семья» еще один - под названием «История голубого бриллианта» (переводчик неизвестен). В 1897 г. в «Литературном приложении “Нивы”» был напечатан перевод «Нищий урод», а в самом журнале «Нива» - «Союз рыжеволосых». 
В 1898 г. выходит журнал «Нива» (№ 5) с переводным произведением «Профессор Мориарти». В этом же году в типографии «Владимирская» в Санкт-Петербурге был отпечатан первый сборник новелл Конан Дойла под названием «Записки знаменитого сыщика».

Позднее к творчеству английского писателя обращались такие известные переводчики, как А.Л. Толстая (младшая дочь Л.Н. Толстого), Н.Д. Облеухов, А.П. Репина, Г.А. Чарский, Н.К. Тренева, К.И. и Н.К. Чуковские, В.И. Стенич, Д.Г. Лившиц и др. Многие переводы, выполненные ими, неоднократно публиковались на протяжении длительного периода в различных советских переизданиях авторских сборников и отдельных произведений. На более поздних этапах восприятия творчества Конан Дойла его произведения переводили В. Михалюк, В. Штенгель, Г. Панченко, Е. Корнеева и др.

Как уже было сказано выше, Конан Дойл приобрел особую популярность в России в начале XX в., в период общественной реакции, после поражения революции 1905 г. Вероятнее всего, это связано с напряженной обстановкой в стране, беспорядками, весьма высоким уровнем преступности, с которым полиция, обремененная излишней бюрократией, не всегда была в состоянии справиться. Появившийся в детективной литературе образ сыщикаинтеллектуала, способного распутать самые загадочные и сложные преступления, привлек внимание русских читателей, которые, безусловно, обратили внимание как на увлекательное содержание детективных новелл, так и на безукоризненное изложение и стиль автора, что вызывало интерес даже со стороны серьезного читателя.

Говоря о других причинах популярности Конан Дойла в России начала XX в., следует отметить тот факт, что в восприятии его творчества сформировались две противоположные тенденции. Многие критики пытались понять, чем же так интересны читателям Шерлок Холмс и детективная литература в целом, и называли в связи с этим прежде всего традиционный авантюрный сюжет, центром которого являлось преследование сыщиком преступника. Причем сыщик периодически попадает в ловушку, но всегда спасается и находит преступника. Отмечалась и роль традиционного места действия детективных рассказов Конан Дойла: различные подземелья, потайные комнаты, секретные ходы. Интерес вызывало и то, что сыщицкая новелла английского автора активно использовала в своих сюжетах описание новейших изобретений, современных средств коммуника- 
ции (такие как телеграф, телефон), откликаясь на научные достижения в различных областях знания. Но главным было необычайное обаяние созданного Конан Дойлом образа сыщика. К.И. Чуковский писал об этом: «Этот романтический, нежный, рыцарственный образ вдруг, на наших глазах, изменяется, перерождается, эволюционирует, отрывается от самого создателя, Конан Дойла <...> и как миф, как легенда начинает самостоятельно жить среди нас» [5. С. 46]

Действительно, главный герой детективных новелл Дойла вошел в жизнь русских читателей первой половины XX в. и занял свое место не только в литературе, но и культурной и даже бытовой сфере. Книги о Шерлоке Холмсе переводились и печатались одна за другой, в обществе создавались различные клубы любителей Шерлока Холмса, общества почитателей детективов, дети играли в главных детективных героев, которые являлись кумирами для них.

На фоне небывалой востребованности детективных сочинений К. Дойла и попыток ее объяснения названными выше факторами именно в начале XX в. русская критика и юмористика начинают бороться с «пинкертоновщиной» посредством развенчания и пародирования Шерлока Холмса, главного героя детективных произведений английского писателя [7. С. 344-345]. Тогда и появился термин «пинкертоновщина», означавший низкосортную вульгарную литературу о приключениях известных сыщиков, таких как Шерлок Холмс, Нат Пинкертон и т.д. С точки зрения ряда критиков, «пинкертоновщина», так же как и порнографическая литература, способствовала отвлечению читателей от общественных проблем, связанных с революцией. Одновременно высказывались мнения, умалявшие роль К. Дойла в становлении и развитии детективного жанра. Так, А.И. Куприн отозвался о творчестве английского писателя следующим образом: «Конан Дойль, заполнивший весь земной шар детективными рассказами, все-таки умещается вместе со своим Шерлоком Холмсом, как в футляр, в небольшое гениальное произведение Э. По - «Преступление на улице Морг» [8. С. 608].

${ }^{1}$ Об этом же в середине ХХ в. писали П.П. Громов и Б.О. Костелянец в статье «Шерлок Холмс и его приключения»: «Образ, созданный Дойлем, давно отделился от создавшего его автора и зажил в восприятии читателя совершенно самостоятельно не как литературный персонаж, а как реальный человек со своим отношением к жизни, со своими взглядами на вещи и события» [6. С. 3]. 
Тенденция официально негативного отношения к детективу и сочинениям Конан Дойла прочно и надолго прижилась в Советской России. Так, в заметке, опубликованной в «Литературной газете» за 10 февраля 1971 г., утверждалось, что жанра детектива, как такового, вообще нет, «...само это слово настолько опорочено, что хотелось бы его запретить» (цит. по: [9. С. 132]). Хотя в данной статье нет упоминания о Конан Дойле, она посвящена жанру детектива в целом как явлению весьма легкомысленному, с которым необходимо вести активную борьбу. Такой подход, конечно, можно объяснить идеологией, которая пропагандировалась в СССР и согласно которой литература должна выполнять воспитательные, агитационные функции, не отвлекая читателей от классовой борьбы и коммунистического строительства. Понятно, что детективные рассказы Конан Дойла не вписывались в социалистическую систему ценностей, и само слово «детектив» вызывало официально только негативную реакцию.

Наконец, обратимся к истории формирования еще одного уровня рецепции Конан Дойла в России, складывавшегося параллельно переводческой и критической рецепции - к типологическим схождениям детективных сочинений английского писателя с произведениями русских авторов. В России конца XIX - первой половины $\mathrm{XX}$ в. появилось множество подражаний английскому мастеру детективных новелл, которые также оказались весьма востребованными у широкой читательской аудитории. Достаточно упомянуть М.Д. Ордынцева-Кострицкого, который пытался адаптировать творчество английского писателя к российским реалиям XX столетия. Его основные сочинения создавались в период с 1887 по 1934 г., наиболее известное его произведение - «Тайна негатива» из сборника «За счастьем, золотом и славой», в котором отчетливо прослеживаются параллели в изображении главных героев с образом Шерлока Холмса.

Ярким подражателем Конан Дойла можно считать П. Никитина, который обращается к образу Шерлока Холмса в рассказах, составивших сборник «Сверхсыщик», в цикле публикаций «Новейшие приключения Шерлока Холмса», в книге «По следам преступника». Русский автор пытался подать свои детективные сюжеты в пародийном и юмористическом ключе, хотя его произведения в цикле «Новейшие приключения Шерлока Холмса в России» (1908г.) пред- 
ставлены как «русская холмсиана». В это же время появляется множество произведений других русских авторов, рассказывающих о приключениях Шерлока Холмса. Помимо упомянутых выше, можно назвать, например, «Приключения Шерлока Холмса против Ната Пинкертона в России» (1908) П.П. Орловца (он же П.П. Дудоров).

Достаточно сложно определить точную периодизацию рецепции детективного творчества Конан Дойла в России, прежде всего, именно в силу его необычайной популярности. Тем не менее анализ критических отзывов и переводов его сочинений позволяет выделить четыре этапа восприятия детективных сочинений английского писателя. Первый приходится на конец XIX - начало XX в. (18931910), его можно определить как наиболее плодотворный и многоуровневый в процессе освоения творчества английского писателя русской культурой и литературой: произведения Конан Дойла публикуются и обсуждаются в различных журналах, приложениях, переводчики используют разные стратегии, одни и те же произведения переводятся по нескольку раз. Именно в это время, кроме названных выше, были опубликованы переводы «Скаковая лошадь» (подписан: Б.Е.), «Танцующие фигуры» (подписан: В.К.), «Золотое пенсне» «Два пятна», «Приключение» в переводе М. Ратынской, «Три корреспондента» в переводе М. Полторацкой, «Собака Баскервилей», переведенная Е.Н. Ломиковской «Второе пятно» (подписан: 3.М.). В «Вестнике иностранной литературы» за 1904 г. опубликованы все произведения из цикла «Возвращение Шерлока Холмса» кроме «Второго кровавого пятна», которое будет напечатано годом позже в № 3. На рубеже веков появляются первые сборники детективных новелл Конан Дойла на русском языке, например «Записки знаменитого сыщика», в который вошли «Серебряная звезда», «Роковое письмо» и «Аристократы-убийцы» (1898), сборник 1901 г. с аналогичным названием, включавший такие произведения, как «Изуродованный человек», «Постоянный пациент». «Морская драма», «Желтое лицо», «Неудачная мистификация» и «Роковая тайна». Далее вплоть до 1910 г. в России ежегодно выходили сборники с новеллами о Шерлоке Холмсе. Кроме переводческой и критической рецепции детективного творчества Конан Дойла в России рубежа XIX$\mathrm{XX}$ вв., можно говорить о многих подражаниях русских авторов английскому писателю. 
Следующий этап, с 1911 по 1929 г., характеризуется некоторым снижением интереса к детективным произведениям Конан Дойла, особенно заметным это становится после Октябрьской революции, которая сформировала отрицательное отношение к жанру детектива как абсолютно безыдейной литературе. Тем не менее полного исчезновения детективной литературы как жанра не произошло, на что указывает тот факт, что в России 1910-1920-х гг. периодически появлялись статьи о Конан Дойле и новые переводы его детективных новелл, переведенных и не переведенных ранее: «Голубой карбункул», «Пестрая банда», «Желтое лицо», «Глория Скотт», «Горбун», «Случай с переводчиком», «Исчезновение леди Френсис Карфэкс», «Человек с побелевшим лицом».

В течение 1930-1960-х гг. в России неоднократно переиздавалось лишь несколько сочинений - «Собака Баскервилей», «Голубой карбункул», «Знак четырех», «Записки о Шерлоке Холмсе», «Пляшущие человечки» и некоторые другие - в адаптированном переводе (как правило, в серии «Библиотека приключений») или как «книга для чтения на английском языке». Изредка выходили из печати научно-фантастические сочинения Конан Дойла. Первое собрание сочинений английского писателя вышло в СССР только в 1966 г. в 8 томах (под редакцией М. Урнова).

Следующий этап можно ограничить 1970-2010 гг. На это время приходится «возвращение» Конан Дойла в Россию, которое начинается в конце 1970-х - 1980-е гг., когда из печати вышло несколько изданий избранных сочинений писателя в осуществленных ранее переводах. Например, «Записки о Шерлоке Холмсе» появлялись благодаря деятельности различных издательств с 1974 по 1984 г. ежегодно, а затем в 1986, 1987, позже в 1989 г., 1990, 1991, 1993, 1997-2000 гг. Настоящий издательский и переводческий бум вокруг детективного творчества Конан Дойла в России берет отсчет от 1990-х гг., когда был опубликован целый ряд его собраний сочинений, избранных сочинений, сборников детективных рассказов. В 2000-2010-х гг. этот ряд пополнился еще шестью (известными нам) собраниями.

Таким образом, становится понятно, что положение детективного жанра в русской литературе в целом, как и детективное творчество Конан Дойла в частности, неоднозначно: с одной стороны, наблюдалась и наблюдается невероятная популярность его сочинений 
и подражаний им, особенно среди читателей среднего класса. С другой стороны, очевидны резкая критика и негативное восприятие детективных произведений Конан Дойла критикой и государственной издательской политикой практически на протяжении всей истории Советского Союза. Однако, как справедливо утверждает Л.П. Дмитриева, «к поэтике детектива невозможно применять категории “высокой” литературы и понятия “моральное/аморальное”. Классическая литература создавала пространство для заострения нравственных противоречий, их проблематизации и разрешения. Детективная литература апеллирует к игровому началу, посвящена представлению нового типа повествования, имеющего целью "удовлетворение особой интеллектуальной потребности, которую не могут удовлетворить произведения других жанров"» [10. С. 59]. Изучение восприятия детективных новелл Конан Дойла в России представляет собой сложную историко-литературную проблему, решение которой видится в системном подходе, что позволит пролить свет на сложные вопросы взаимодействия классической и массовой литературы, а также поставить вопрос о жанровой взаимосвязи двух литературных традиций - русской и английской - и восполнить существующие лакуны в этом сложном процессе.

\section{Лumepamypa}

1. Энциклопедический словарь английской литературы XX века / отв. ред. А.П. Саруханян; Ин-т мировой литературы им. А.М. Горького РАН. М., 2005.

2. Энциклопедия литературных терминов и понятий / гл. ред. и сост. А.Н. Николюкин. М., 2001.

3. Уголовный роман. Из литературных запасников / сост. А. Рейтблат. М., 1992.

4. Матвеенко И.А. Восприятие английского социально-криминального романа в русской литературе 1830-1900-х гг. Томск, 2014.

5. Чуковский К.И. Нат Пинкертон и современная литература. М., 1910.

6. Громов П.П., Костелянеи Б.О. Записки о Шерлоке Холмсе. Артур КонанДойль // Шерлок Холмс и его приключения. Л., 1946.

7. Литературная энциклопедия. Коммунистическая академия. Секция литературы, искусства и языка; под ред. И.М. Беспалова, П.И. Нусинова и др. М., 1930. T. 3 .

8. Куприн А.И. Собрание сочинений: в 6 т. М., 1958. Т. 6.

9. Антонов С.П. От первого лица. М., 1973.

10. Дмитриева Л.П. «Забытые» детективы» Эдгара По // Текст. Книга. Книгоиздание. 2012. № 2. С. 51-59. 


\section{RECEPTION OF ARTHUR CONAN DOYLE'S DETECTIVE NOVELS IN RUS- SIA: SETTING THE PROBLEM}

Text. Book. Publishing, 2016, 1 (10), pp. 73-85. DOI 10.17223/23062061/10/5

Mironova Veronika E. Tomsk Polytechnic University (Tomsk, Russian Federation). E-mail: veronicka84@yandex.ru

Keywords: Arthur Conan Doyle; reception; levels of reception; detective novel; Russian literature.

In the given article the problem of Arthur Conan Doyle's detective novels reception in Russia is under study.

Writings of the English author Arthur Conan Doyle (1859-1930) are of particular interest in the context of the history of Russian-English literary relations development from the end of the 19th century to the present day. Despite the fact that Doyle wrote works of various genres his name is frequently associated with detective literature.

The purpose of the given research is to demonstrate the most important periods of his detective novels popularity on different levels of reception, such as translation reception, interaction and revision of his writing basis in works of Russian authors, attitude of critics to detective literature and Doyle as a writer in particular.

When studying literary preferences in Russia, it is necessary to notice that at the turn of the 19th and 20th centuries with the growth of literacy among democracy population literature with a detective as a main character successfully solving crimes was spreading quite rapidly. In this period of time the detective became a fully complete genre. This genre was gradually gaining its followers and admirers among clerisy.

However, when studying the history of the given genre it is possible to single out a range of contradictions and controversial attitudes of both critics and readers.

The detective genre gained its special popularity at the beginning of the 20th century.

The socio-aesthetic phenomenon of detective literature attracted attention of a range of authors, such as S.M. Eisenstein, K.I. Chukovsky and others; nevertheless, there is no common generally recognized detective genre theory. Some authors called it an intellectual crossword, others a mixture of literature and playing, the third an industrial novel from the life of CID employees. However, elements of a detective are an integral part of many books of "Great Literature", for instance, fiction of F. M. Dostoevsky, O. Balzac, Ch. Dickens and others.

As the given research is devoted to the reception history of detective literature written by Arthur Conan Doyle, it is necessary to emphasize that reception study of detective novels of the English writer is considered to be rather significant from the point of view of aesthetics, poetics and typology of the genre development.

In the frame of the given project it is necessary to reflect principles, nature and evolution of detective novels reception by Russian writers and translators, pointing out the main periods of detective writing reception. Each period of the studied receptive history has its own specific character and logic of development. All these aspects correspond to the interest of modern literary studies to the problems of comparative studies, theory and history of translation, receptive aesthetics, multicultural dialogue, interaction between Russia and England within the framework of popular and classic literature, capital and regional literature. 


\section{References}

1. Sarukhanyan, A.P. (ed.) (2005) Entsiklopedicheskiy slovar' angliyskoy literatury $X X$ veka [The Encyclopedic Dictionary of English literature the 20th century]. Moscow: Institute of World Literature.

2. Nikolyukin, A.N. (2001) Entsiklopediya literaturnykh terminov i ponyatiy [The encyclopedia of literary terms and concepts]. Moscow: RAS.

3. Reytblat, A. (1992) Ugolovnyy roman. Iz literaturnykh zapasnikov [The criminal novel. From literary storerooms]. Moscow: IRDASH.

4. Matveenko, I.A. (2014) Vospriyatie angliyskogo sotsial'no-kriminal'nogo romana $v$ russkoy literature 1830-1900-gg. [Perception of the English social-criminal novel in Russian literature, 1830-1900]. Tomsk: Tomsk State University.

5. Chukovsky, K.I. (1910) Nat Pinkerton i sovremennaya literatura [Nat Pinkerton and modern literature]. Moscow: Sovremennoe tvorchestvo.

6. Gromov, P.P. \& Kostelyanets, B.O. (1946) Sherlok Kholms i ego priklyucheniya [Sherlock Holmes and his adventures]. In: Conan Doyle, A. Zapiski o Sherloke Kholmse [Notes about Sherlock Holmes. Arthur Conan Doyle]. Leningrad: Molodaya gvardiya.

7. Bespalov, I.M. et al. (eds) (1930) Literaturnaya entsiklopediya [The Literary Encyclopedia. The Communist Academy. Section of literature, art, and language]. Vol. 3. Moscow: Communist Academy.

8. Kuprin, A.I. (1958) Sobr. soch.: v 6 t. [Collected Works. In 6 vols]. Vol. 6. Moscow.

9. Antonov, S.P. (1973) Ot pervogo litsa [From the first person]. Moscow: Sovetskiy pisatel'.

10. Dmitrieva, L.P. (2012) Forgotten novels by Edgar Poe. Tekst. Kniga. Knigoizdanie - Text. Book. Publishing. 2. pp. 51-59. (In Russian). 